\title{
$n^{\circ}$ 2012-22
}

\section{The Cyclicality of the Separation and Job Finding Rates in France}

\author{
J.-O. HAIRAULT ${ }^{1}$ \\ T. LE BARBANCHON ${ }^{2}$ \\ T. SOPRASEUTH ${ }^{3}$
}

June 2012

Les documents de travail ne reflètent pas la position du CREST et n'engagent que leurs auteurs. Working papers do not reflect the position of CREST but only the views of the authors.

\footnotetext{
1 PSE, Université Paris I, et IZA. Email : joh@univ-paris1.fr

2 CREST, 15 Boulevard Gabriel Péri, 92245 Malakoff Cedex, France. Email : thomas.lebarbanchon@ensae.fr

3 Université de Cergy-Pontoise, THEMA \& CEPREMAP. Email : thepthida.sopraseuth@u-cergy.fr
} 


\title{
The cyclicality of the separation and job finding rates in France
}

\author{
Jean-Olivier Hairault* $\quad$ Thomas Le Barbanchon ${ }^{\dagger} \quad$ Thepthida Sopraseuth ${ }^{\ddagger}$
}

June 2012

\begin{abstract}
In this paper, we aim to shed light on the relative contribution of the separation and job finding rates to French unemployment at business cycle frequencies by using administrative data on registered unemployment and labor force surveys. We first investigate the fluctuations in steady state unemployment, and then in current unemployment in order to take into account the unemployment deviations from equilibrium. Our results show the dominant role of the job finding rate in accounting for French unemployment fluctuations. The contribution of the job finding rate amounts to about two-thirds of the unemployment dynamics. With the two data sets, we find that both rates contributed to unemployment fluctuations during the nineties, while the job finding rate has been more significant in the last decade. In particular, the last business cycle episodes, including the last recession, exacerbate the role of the job finding rate.
\end{abstract}

Keywords: unemployment variability, job separation; job finding, worker flows JEL classification: E24, J6

\footnotetext{
*PSE, University of Paris I, and IZA. Email: joh@univ-paris1.fr

${ }^{\dagger}$ Crest. Email: thomas.le-barbanchon@ensae.fr

‡Université de Cergy-Pontoise, THEMA \& Cepremap. Email: thepthida.sopraseuth@u-cergy.fr
} 


\section{Introduction}

The analysis of unemployment dynamics between outflows and inflows has recently received a lot of attention. Using CPS data, Shimer (2012) claims that, since 1948, inflows into unemployment have played a minor role in accounting for unemployment dynamics in the US, compared to outflows from unemployment. This conclusion for the US has been challenged economy by Fujita \& Ramey (2009) and Elsby et al. (2009) who show that inflows to unemployment matters quantitatively. This conclusion also applies to UK unemployment, according to Petrongolo \& Pissarides (2008) and Smith (2011).

This paper aims to identify the driving forces behind unemployment dynamics in France. As pointed out by Elsby et al. (2008), this country is particularly interesting because it exemplifies the polar case of a rigid labor market with strict employment protection laws (Allard (2005)) and low rates of labor reallocation (Blanchard \& Portugal (2001)). Two previous papers have already documented the cyclicality of the labor market transitions in France. Firstly, Petrongolo \& Pissarides (2008) investigate the contribution of entry and exit rates to and from French unemployment to unemployment fluctuations, using a monthly administrative dataset based on unemployment registers between 1991 and 2007. They find that the relative contribution of the outflow rate from unemployment is dominant. Secondly, Elsby et al. (2008) analyze unemployment dynamics using aggregate annual data on shortterm unemployment based on French Labor Force Surveys (hereafter LFS) between 1975 and 2008. They find a 50:50 inflow/outflow split. ${ }^{1}$ These quite opposing results could be due to different datasets. Moreover, as far as data are concerned, each paper suffers from some limits, which could bias their conclusion. In this paper, we aim to shed light on the relative contribution of the transition rates to French unemployment at business cycle frequencies by using datasets more in line with international standards.

Petrongolo \& Pissarides (2008) use administrative data based on unemployment registers (Statististiques Mensuelles sur le Marché du Travail, hereafter named STMT). The STMT, which is an aggregate count, suffers from several problems. First, some people continue to work while being registered in the Public Employment Service (PES). These workers are counted in the unemployment total, representing roughly 30\%. This leads to counting some artificial outflows (when these workers leave the registers) and misses some real inflows of these workers already registered at the PES. This is problematic, as these artificial and real flows are important and cyclical (Abdouni et al. (2011)). Secondly, administrative rules (such as reporting at the end of each month) generate spurious transitions in the STMT. The unemployed who do not report their situation in due time are deregistered. They can register again after a few days, so this generates high frequency movements, which do not represent real labor transitions. Thirdly, changes in unemployment legislation (such as eligibility for unemployment benefits and activation schemes) have direct, even mechanical, impacts on inflows and outflows in STMT. This is problematic as these legal changes are not necessarily related to business conditions. Fourthly, in STMT, it is not possible to control consistently for

\footnotetext{
${ }^{1}$ Elsby et al. (2008) find a 20:80 inflow/outflow split of unemployment variation for Anglo-Saxon countries. For Continental European and Nordic countries, a 50:50 split is observed.
} 
the origin of inflows and the destination of outflows. Then the cyclical analysis captures both transitions to employment and to inactivity, which blurs the interpretation. We therefore use another administrative dataset (Fichier Historique, hereafter FH dataset) which is subject to the third problem, but relieves us from the other three concerns (mainly because it is an individual panel).

In general, international evidence on the source of unemployment dynamics relies on Labor Force Surveys or assimilated datasets. Moreover, only LFS, with their detailed information on individual characteristics, can be used in future studies on more disaggregated data (labor market transitions with inactivity or across age groups, gender, industry). Elsby et al. (2008) rely on the Labor Force Surveys of different countries, including France, provided in a standardized way by OECD (2008), but at the expense of considering annual time series. We extend Elsby et al. (2008) by providing infra-annual labor market transitions, using the retrospective calendar of the French LFS, which is more in line with previous studies on the US and UK economies.

We then build datasets covering several recession and expansion episodes, including the last severe recession, using both administrative data and Labor Force Surveys. We first investigate the analysis of fluctuations in steady state unemployment along the lines of Shimer (2012) and Fujita \& Ramey (2009). This analysis strategy is valid as long as the equilibrium unemployment provides a good proxy for actual unemployment. However, both time series can differ substantially, especially in a labor market with low workers' flows, which is the case in France. Whereas Petrongolo \& Pissarides (2008) deal with this issue by excluding periods with large discrepancies between changes in actual and steady state unemployment, we explicitly consider a dynamic analysis, thereby taking into account the effect of past changes in transition rates on actual unemployment. This is the strategy followed by Smith (2011) and Elsby et al. (2008) who apply a dynamic analysis to UK data and to OECD data respectively.

As far as administrative data are considered, it is not possible to measure transitions between employment and inactivity. A comprehensive three-state analysis cannot then be undertaken. This is why Petrongolo \& Pissarides (2008) can only provide an analysis of unemployment dynamics between total outflows from and total inflows to unemployment. Elsby et al. (2008) using duration-based flows face the same limit. In this paper, we adopt another strategy by focusing on transitions between employment and unemployment, i.e. a two-state view of labor market transitions, as in Fujita \& Ramey (2009). Though information on transitions between employment and inactivity would be available in LFS data, we prefer to leave aside this information in order to use two different, but comparable, data sources as robustness check of our results. This is all the more important in that there are missing data for the LFS dataset between 2002 and 2004.

Adopting this two-state view of labor market transitions, we will refer to the separation rate for transitions from employment to unemployment and to the job finding rate for transitions from unemployment to unemployment. This allows us to measure precisely the relative contributions of well-identified transitions. From Shimer (2012) and Smith (2011), it is well-established that these transitions explain more than two-thirds of the variability 
of US and UK unemployment, whatever the relative role of the ins and outs. Though this result would deserve to be verified on French data, we believe that the two-state approach can be considered as capturing the core dynamics of unemployment. ${ }^{2}$

Both data sets lead to quite similar results that establish the dominant role of the job finding rate in the fluctuations in French unemployment. We find that its contribution is more important than suggested by the results shown by Elsby et al. (2008), though less than in Petrongolo \& Pissarides (2008). The contribution of the job finding rate amounts to about two-thirds of the unemployment dynamics. With the two data sets, we find that both rates contribute to unemployment fluctuations during the nineties, while the last decade actually gives more importance to the job finding rate. In particular, the last business cycle episode, including the last recession, exacerbates the role of the job finding rate.

The paper is organized as follows. In Section 2, we present the administrative and LFS data, the methodology and the computation behind the French transition rates involving employment and unemployment. We then compute in the next section the relative contribution of separation and finding rates to changes in both equilibrium and actual unemployment. The last section concludes.

\section{Transitions between employment and unemployment}

Along the lines of Petrongolo \& Pissarides (2008) and Elsby et al. (2008), both administrative data and individual record files from LFS are used to analyse the contribution of separation and job finding changes to the dynamics of French unemployment.

\subsection{Data}

\subsubsection{Administrative data}

We rely on administrative data produced by the French Public Employment Service. The administrative data (Fichier Historique, FH) we consider is an individual panel, available on a monthly basis from 1994 onwards. It allows us to check whether registered unemployed workers are actually working and to track their transitions in/out of employment even if they stay registered. This information gives a crucial advantage to the FH data compared to the STMT administrative data used by Petrongolo \& Pissarides (2008). We then provide a more accurate and precise picture of unemployment dynamics. In addition, the FH data give some information about the labor status (employed or not) prior to registering with the agency and after exiting the register. This allows us to measure transitions between employment and unemployment states, and not the ins and outs of the unemployment, which put together transitions from and to employment and inactivity.

\footnotetext{
${ }^{2}$ Considering a three-state approach or individual characteristics such as age, gender or ability is left for further research.
} 


\subsubsection{Labor Force Survey}

As it is crucial to also provide a dataset in which information on individual characteristics is available, we then compute workers' flows using LFS. We use LFS from 1991 through 2010. ${ }^{3}$ The survey was redesigned in 2003. Prior to 2003, individuals were surveyed each year, three years in a row. After 2003, each individual is surveyed every quarter, six quarters in a row. The redesign implied huge changes in the process of the survey, which resulted in data problems for the first two years after the redesign. As a result, we chose to drop the data from 2003 and 2004. Our LFS sample covers the periods 1990-2002 and 2004-2010. Our estimates of monthly labor market transitions are based on a retrospective calendar that is filled in by the individual the first time he is interviewed. ${ }^{4}$ He reports his labor status one month prior to the interview, two months, and so on up to 12 months prior to the interview. Several studies have shown that retrospective data are biased by recall errors. We propose an intuitive and innovative strategy to correct the data for recall errors. ${ }^{5}$

\subsection{Measuring instantaneous transition rates}

To construct the series of worker flows, we refer to the theoretical framework proposed by Shimer (2012). This framework rests on two assumptions. First, we do not take into consideration the transitions of the inactive (to or from inactivity), or transitions from job to job. Our analysis focuses on monthly transitions from employment to unemployment and unemployment to employment. Moreover, we assume, that during a given period, all the unemployed have the same opportunity to return to work and all employees the same risk of losing their job. Taking into account the heterogeneity of workers that influences the losses and reversals of employment is beyond our study.

As in Shimer (2012), time is continuous, but the labor market status is observable only in a discrete manner, in our paper at the end of every month. $t \in\{0,1,2, \ldots\}$ corresponds to the date when the situation is observed, while $\tau \in[0,1]$ is the duration since the last observation date. LFS and administrative data give the opportunity to measure the probability of returning to work and the probability of job loss by over a given month. Nevertheless, these probabilities may underestimate the magnitude of labor flows, to the extent that several transitions to and from employment may be between $t$ and $t+1$. Several solutions have been proposed to correct the temporal aggregation bias. The simplest is to reduce the time between two measurements as done by Elsby et al. (2009) who consider transitions weekly. But this is not always possible. Shimer (2012) proposes to deducing the instantaneous transition rates from the observed monthly transitions. We follow his approach to correct both datasets, FH and LFS.

\footnotetext{
${ }^{3}$ The LFS has been in existence since 1950, but data on monthly transitions have been collected since 1991.

${ }^{4}$ Using the retrospective calendar in LFS 1991 and 2005, we can retrieve monthly data on labor market transitions in 1990 and 2004.

${ }^{5}$ See Appendix A.
} 
Let $e_{t+\tau}$ denote the number of employed workers at date $t+\tau, u_{t+\tau}$ the number of unemployed workers at the same date $t+\tau$. For $t \in\{0,1,2, \ldots\}$ and $\tau \in[0,1]$, the dynamics of unemployed workers are given by the following law of motion:

$$
\dot{u}_{t+\tau}=e_{t+\tau} \lambda_{t}^{E U}-u_{t+\tau} \lambda_{t}^{U E}
$$

Unemployment increases when employees lose their jobs and decreases when the unemployed return to work. The quantities for understanding the dynamics of unemployment are the separation rate and the job finding rate (Equation (1)). We adopt the same notations as Shimer (2012) with $\lambda_{t}^{U E}$ the instantaneous probability of finding a job (finding rate) and $\lambda_{t}^{E U}$ the instantaneous probability of losing a job (separation rate). Note that both instantaneous rates are considered constant between date $t$ and $t+1$ (over the month). The corresponding transition probabilities $\Lambda_{t}^{A B}$ of at least a transition during period $t$ are $\Lambda_{t}^{A B} \equiv 1-e^{-\lambda_{t}^{A B}}$ with $A=\{E, U\}, B=\{E, U\}$ and $A \neq B$.

To calculate these transition rates, we first consider the flow $N_{t}^{A B}(\tau)$ of workers that are in the state $A$ at the time $t$ and in the state $B$ at the time $t+\tau$. Follonwing the terminology used by Shimer (2012), we will refer to these numbers as the gross flows of the labor market. Let $n_{t}^{E U}(\tau)\left(n_{t}^{U E}(\tau)\right)$ denote the share of employed workers (unemployed workers) in period $t$ who are unemployed (employed) in period $t+\tau$ :

$$
\begin{aligned}
& n_{t}^{E U}(\tau)=\frac{N_{t}^{E U}(\tau)}{E_{t}} \\
& n_{t}^{U E}(\tau)=\frac{N_{t}^{U E}(\tau)}{U_{t}}
\end{aligned}
$$

where $E_{t}$ and $U_{t}$ indicate the measured stocks of employed and unemployed workers, respectively. A problem arises in the two-state case in the computation of stocks of employed and unemployed workers. Though we focus on transitions between employment and unemployment, and never consider transitions from and to inactivity, it cannot be ignored that employed and unemployed workers can become inactive. For total employment, for instance, shall we consider that $E_{t}=N_{t}^{E E}(\tau)+N_{t}^{E U}(\tau)+N_{t}^{E I}(\tau)$ which is consistent with observed employment? or shall we ignore inactivity, thereby using $E_{t}=N_{t}^{E E}(\tau)+N_{t}^{E U}(\tau)$, which is internally consistent with the two-state model?

The choice is not innocuous for the computation of separations. In Shimer (2012), in the two-state case, $n_{t}^{E U}(\tau)=\frac{N_{t}^{E U}(\tau)}{N_{t}^{E E}(\tau)+N_{t}^{E U}(\tau)}$ while in Fujita \& Ramey (2009), even in the two-state case, $n_{t}^{E U}(\tau)=\frac{N_{t}^{E U}(\tau)}{N_{t}^{E E}(\tau)+N_{t}^{E U}(\tau)+N_{t}^{E I}(\tau)}=\frac{N_{t}^{E U}(\tau)}{E_{t}}$. We refer to their computation as the hybrid two-state case.

In our paper, we consider the hybrid two-state case, as in Fujita \& Ramey (2009). Indeed, administrative data provide values for the stock of unemployed workers $U$, inflows and outflows, but the stock of employed workers $E$ has to be taken from an external source (INSEE, total employment, wage-earning workers) and the proportion of workers who keep their job is unknown. In order to make LFS flows consistent with the ones obtained from administrative 
Table 1: From gross flows to instantaneous transition rates

\begin{tabular}{lcc}
\hline \hline & FH & LFS \\
\hline 1. Monthly gross flows $N_{t}^{A B}$ & external source $E$ & \\
2. Correct for recall error & & yes \\
3. Seasonally adjust the time series (x12) & yes & yes \\
4. Correct for time aggregation (Shimer (2012)) & yes & yes \\
5. Quarterly averages & yes & yes \\
Periods & 1994Q1-2010Q4 & 1990Q2-2002Q1 \\
& & 2004Q1-2010Q3
\end{tabular}

data, we apply Equations (2) and (3) to LFS labor market transitions, meaning that the measure of the stocks of past employment and unemployment also includes current flows to and from inactivity.

We then apply Shimer (2012)'s methodology to infer quarterly instantaneous transition rates from monthly gross flows, correcting for time aggregation when necessary. As $N_{t}^{A B}(0)=$ $n_{t}^{A B}(0)=0$ for all $A \neq B$ the differential equation describing the evolution of $n_{t}^{A B}(\tau)$ is:

$$
\dot{n}_{t}^{A B}(\tau)=n_{t}^{A A}(\tau) \lambda_{t}^{A B}-n_{t}^{A B}(\tau) \lambda_{t}^{B A} \quad \forall A \neq B
$$

The solution $n_{t}^{A B}(1)$ to the differential equation (4) is given by:

$$
\begin{aligned}
& n_{t}^{A B}(1)=\lambda_{t}^{A B}\left(\frac{1-e^{-\lambda_{t}^{A B}-\lambda_{t}^{B A}}}{\lambda_{t}^{A B}+\lambda_{t}^{B A}}\right) \\
& n_{t}^{B A}(1)=\frac{\lambda_{t}^{B A}}{\lambda_{t}^{A B}} n_{t}^{A B}(1)
\end{aligned}
$$

It is then possible to recover the transitions rates from Equations (5) and (6):

$$
\begin{aligned}
\lambda_{t}^{A B} & =n_{t}^{A B}(1) \frac{-\log \left(1-n_{t}^{A B}(1)-n_{t}^{A B}(1)\right)}{n_{t}^{A B}(1)+n_{t}^{A B}(1)} \\
\lambda_{t}^{B A} & =\frac{n_{t}^{B A}(1)}{n_{t}^{A B}(1)} \lambda_{t}^{A B}
\end{aligned}
$$

Table 1 summarizes the steps involved in this process.

\subsection{Job finding and separation rates in France}

Figures 1 and 2 show the job-finding probability $\Lambda_{t}^{U E}$ and separation probability $\Lambda_{t}^{E U}$ using administrative data $(\mathrm{FH})$ and LFS respectively, along with the corresponding actual unemployment rate. Notice that the measure of the actual unemployment rate is consistent with 
the definition of unemployment specific to each dataset. Indeed, unemployment is defined as inclusion in the register without employment in $\mathrm{FH}$, and self-reported unemployment in LFS. ${ }^{6}$ The stock of unemployed workers from each dataset is actually greater than the one meeting ILO criteria. As a result, the unemployment rate computed from each dataset differs from the ILO unemployment rate. When we refer to "actual" unemployment, we mean the actual unemployment rate computed from each dataset. Appendix $\mathrm{C}$ shows that changes in our "actual" unemployment rates are consistent with the ones observed for the ILO unemployment rate (with a correlation between both time series of approximately 0.98 for $\mathrm{FH}$ and LFS).

Figure 1: Administrative data $(\mathrm{FH})$ : Transition probabilities (separations $\Lambda^{E U}$ in the upper part, findings $\Lambda^{U E}$ in the lower part) and actual unemployment rate $(u)$
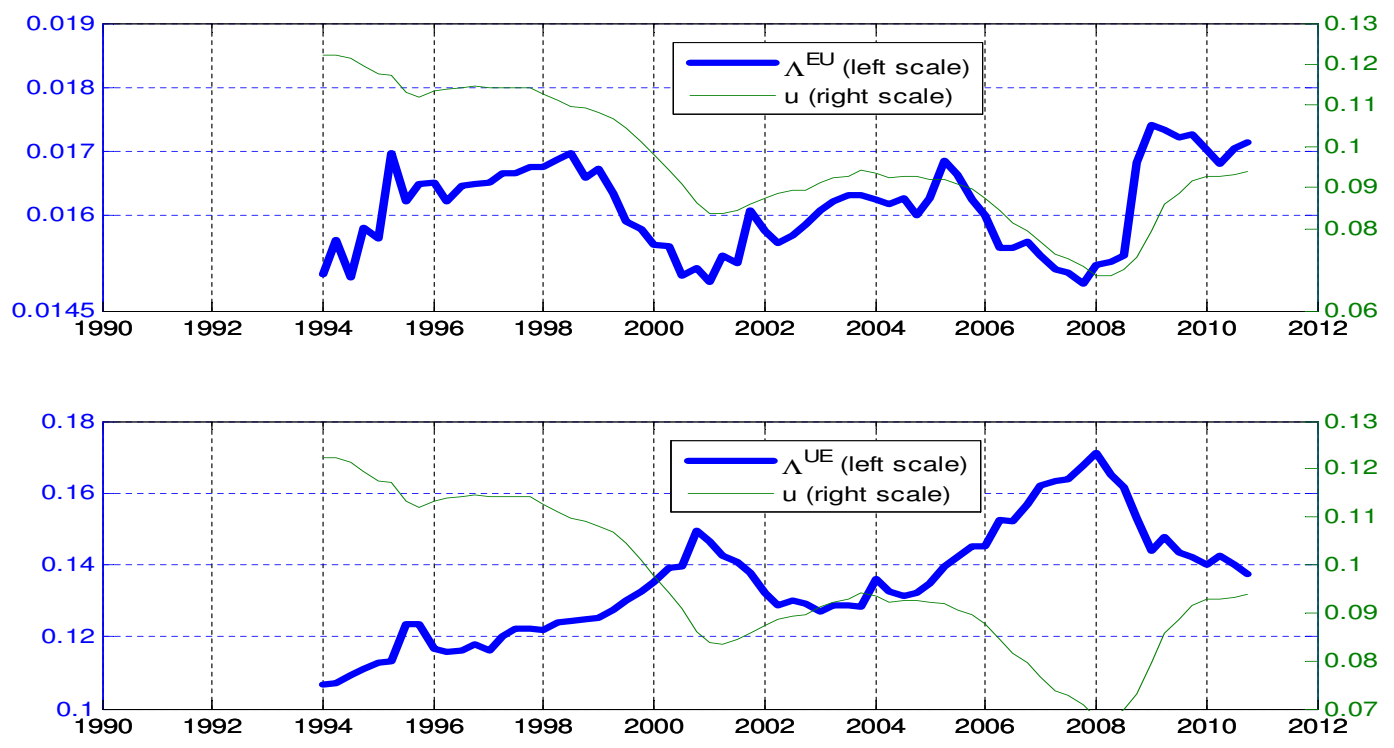

Table 2 shows average separation and finding transition probabilities across datasets. Whatever the dataset, the French workers' flows are characterized by a lower value than the ones computed by Shimer on US data (job finding probability of $46 \%$ and separation probability of $3.5 \%$ in 1948-2004). Using LFS, the French job finding probability amounts to $\bar{\Lambda}^{U E}=7.5 \%$. This value is consistent with an unemployment spell of 13.4 months. This value nearly matches the OECD estimate of 14 months (average duration of unemployment, total, annual data from 1990 to 2009). The separation probability is $\bar{\Lambda}^{E U}=1.2 \%$. LFS estimates

\footnotetext{
${ }^{6}$ In the US CPS, unemployment is associated with the job search (the survey defines unemployment status as "unemployed-looking for a job"). In the French LFS retrospective calendar, there is no information on job search associated with the unemployment status. The survey respondent can report himself as unemployed, whatever his actual job search behavior.
} 
Figure 2: LFS: Transition probabilities (separations $\Lambda^{E U}$ in the upper part, findings $\Lambda^{U E}$ in the lower part) and actual unemployment rate $(u)$
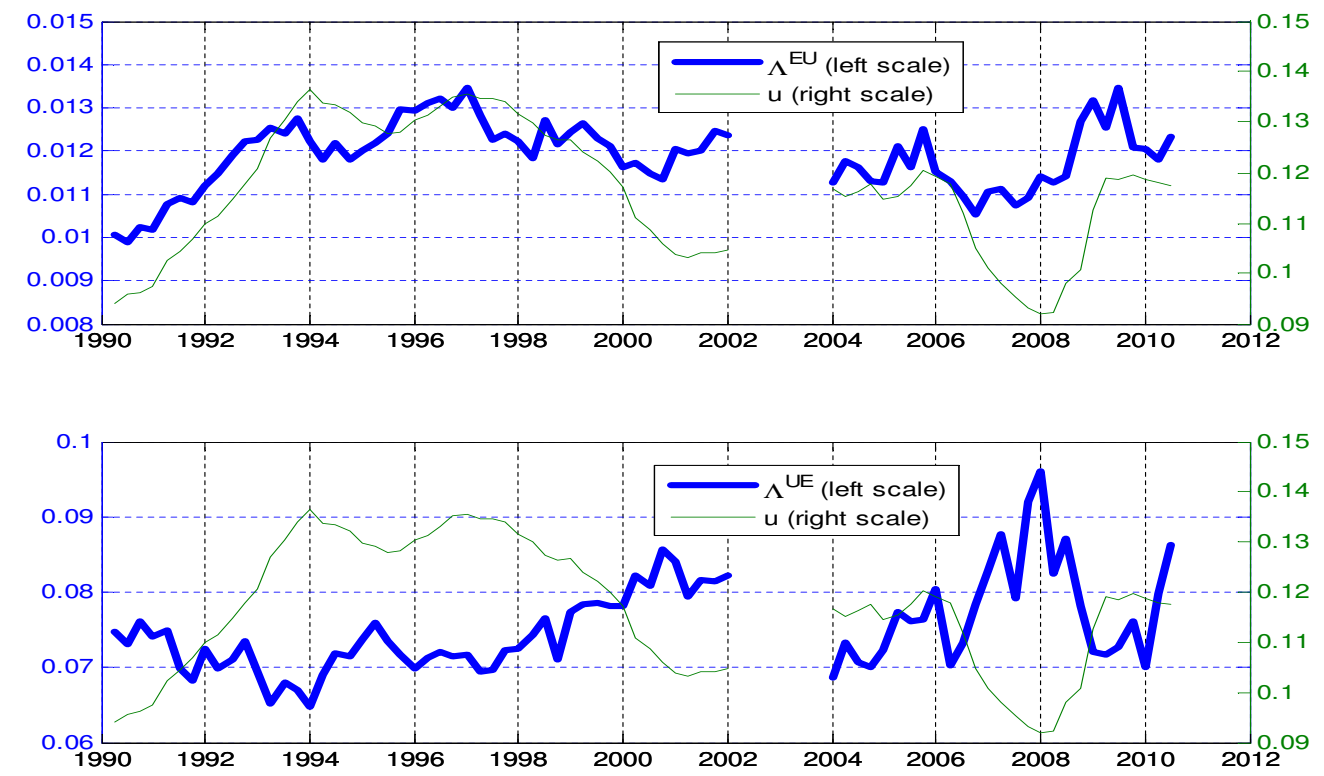

Table 2: Separation and job finding probability

\begin{tabular}{lcc}
\hline \hline Data & average separation prob. $\bar{\Lambda}^{E U}$ & average finding prob. $\bar{\Lambda}^{U E}$ \\
\hline FH (administrative data) & $1.7 \%$ & $13.5 \%$ \\
LFS & $1.2 \%$ & $7.5 \%$ \\
\hline \hline
\end{tabular}

are close to Elsby et al. (2008)'s results on annual data. They show in France an average outflow rate of $7.8 \%$ and inflows of $0.8 \%$ (1975-2005). On the other hand, the transition rates using the administrative records are higher, but still far from their US counterparts. The difference in the finding rate between LFS and FH datasets can be explained by the fact that some unemployed, who are not registered in the PES, as they have exhausted their rights, are still in the LFS. They are the long-term unemployed who typically have lower job finding rates. On the other hand, some workers in job-to-job transitions can claim unemployment benefits without self-declaring as unemployed in LFS, which can explain why the average separation rate is higher when considering administrative data.

In Figures 1 and 2, unemployment dynamics display a high volatility due to subsequent booms and busts. Overall, combining the two datasets, the data span two severe recessions (1990Q4-1994Q2 and 2008Q1-2009Q4) and one mildly recession at the beginning of the 2000's (2001Q4-2004Q1) on the one hand and two expansions (1999Q1-2001Q4 and 2006Q1- 
2007Q4) on the other hand. ${ }^{7}$ Furthermore, a steady dynamic can also be observed between 1995 and 1999. Both transition rates fluctuate with unemployment: the job finding rate negatively moves with unemployment, whereas the separation rate is positively correlated. At this stage, it is difficult to conclude that a particular transition rate contributes more to unemployment volatility than the other. Considering administrative data, the cyclical swings of the transition rates perfectly mirror those of unemployment. The separation rate jumps to relatively high values in recessions, and decreases by a large amount in expansions. The opposite is true for the job finding rate. For LFS data, the rate dynamics are more erratic and, at least visually, less cyclical. However, this statement is less true during the last two cyclical episodes.

\section{Quantitative analysis}

Our objective is now to examine the contributions of the transition rates to unemployment fluctuations, more precisely, to give a quantitative measure of the relative contribution of the separation rate and the finding rate. This analysis is firstly based on the dynamics of steady state unemployment. Acknowledging that this approach is only valid when the transition rates are high enough, a non-steady state analysis is then also proposed.

\subsection{Analysis of steady state unemployment}

In order to examine the cyclicality of the job finding and separation rates, Shimer (2012) uses Equation (1) to infer the expression of the steady state unemployment rate. Indeed, if unemployment is constant, Equation (1) implies that $e_{t+\tau} \lambda_{t}^{E U}-u_{t+\tau} \lambda_{t}^{U E}=0$. Using the assumption about the lack of transition in and out of the labor force, $e_{t+\tau}=1-u_{t+\tau}$ yielding the expression of the steady state unemployment rate:

$$
u_{t}^{S S}=\frac{\lambda_{t}^{E U}}{\lambda_{t}^{E U}+\lambda_{t}^{U E}}
$$

On US data, Equation (9) provides a very good approximation of the end-of-period actual unemployment rate with a correlation between $u_{t}^{S S}$ and the actual unemployment rate of 0.99 . On French data, the correlation is lower (respectively equal to 0.91 and 0.83 for $\mathrm{FH}$ and LFS data) but we consider that it is high enough to preserve the relevance of the steady state approach, at least as a first strategy before considering a non-steady or dynamic analysis.

Using this strong relationship between actual unemployment and steady state unemployment, fluctuations in the equilibrium unemployment rate can be broken down into changes in the separation rate $\lambda_{t}^{E U}$ and the job-finding rate $\lambda_{t}^{U E}$. Along the lines of Shimer (2012),

\footnotetext{
${ }^{7} \mathrm{~A}$ recession (an expansion) is considered as a continuous increase (decrease) in ILO unemployment
} 
we compute the following hypothetical steady state unemployment rate that holds the separation or the job finding rates constant at their historical averages:

$$
\begin{aligned}
u_{t}^{S S_{-} U E} & =\frac{\bar{\lambda}^{E U}}{\bar{\lambda}^{E U}+\lambda_{t}^{U E}} \\
u_{t}^{S S_{-} E U} & =\frac{\lambda_{t}^{E U}}{\lambda_{t}^{E U}+\bar{\lambda}^{U E}}
\end{aligned}
$$

where $\bar{\lambda}^{E U}$ and $\bar{\lambda}^{U E}$ denote the average values of separation and finding rates respectively.

In order to provide a single measure of the contribution of each rate to the changes in unemployment, the method consists in regressing each log-detrended counterfactual steady state unemployment, $d u_{t}^{S S_{-} U E}$ and $d u_{t}^{S S_{-} E U}$, on log-detrended steady state unemployment $d u_{t}^{S S}$ :

$$
\begin{aligned}
\beta^{U E} & =\frac{\operatorname{cov}\left(d u_{t}^{S S}, d u_{t}^{S S \_U E}\right)}{\operatorname{var}\left(d u_{t}^{S S}\right)} \\
\beta^{E U} & =\frac{\operatorname{cov}\left(d u_{t}^{S S}, d u_{t}^{S S}{ }_{-}^{E U}\right)}{\operatorname{var}\left(d u_{t}^{S S}\right)}
\end{aligned}
$$

Petrongolo \& Pissarides (2008), Elsby et al. (2008) and Fujita \& Ramey (2009) prefer to decompose changes in unemployment dynamics into two linear terms, corresponding to the relative contribution of the two transition rates. They rely on the following approximation of steady state unemployment:

$$
\log \left(\frac{u_{t}^{S S}}{u^{S S}}\right)=\left(1-u^{S S}\right) \log \left(\frac{\lambda_{t}^{E U}}{\lambda^{E U}}\right)-\left(1-u^{S S}\right) \log \left(\frac{\lambda_{t}^{U E}}{\lambda^{U E}}\right)
$$

The contribution of the separation (finding) rate is then obtained by regressing the first (second) component of the right-hand side on the deviation of steady state unemployment from its trend. This is an exact variance analysis, whereas Shimer's method is not. But, as truly claimed in Shimer (2012), the sum of the transition rate contributions is close to one when using counterfactual approximations. Actually, these two methods lead to rather similar results, when the same detrending method is used in both cases.

Shimer (2012) and Fujita \& Ramey (2009) actually differ in the detrending method. Detrending may be either through using an HP filter or through first-differentiation. The former uses an HP filter with a relatively high smoothing parameter (equal to $10^{5}$ ), which correspond to a much lower-frequency filter than commonly used in the literature. The latter use a first-difference filter. Actually, reconsidering the transition rates for the US, Appendix B, shows that the two approaches lead to different conclusions only when detrending differs. $^{8}$ We share Shimer (2012)'s opinion: the series in first differences is dominated by

\footnotetext{
${ }^{8}$ Fujita \& Ramey (2009) compare the two detrending methods on the same dataset, but using a lower smoothing parameter equal to 1600 .
} 
measurement errors. This is why we will follow the approach favored by Shimer (2012), based on counterfactual unemployment approximations and, especially, HP filtering with a high smoothing parameter equal to $10^{5}$. Again, we subscribe to Shimer (2012)'s view that a standard filter parameter, typically equal to 1600 for quarterly series, removes too much of the cyclical volatility of the labor market stocks and flows.

The counterfactual (or hypothetical) steady state unemployment rates allow us first to visualize the relative cyclicality of the two transition rates. Figures 3 and 4 plot the cyclical dynamics of the two hypothetical unemployment rates $\left(d u_{t}^{S S_{-} E U}\right)$ and $\left(d u_{t}^{S S_{-} U E}\right)$ relative to the cyclical component of the steady state unemployment. In the first 1990Q4-1994Q2 recession, considering only the LFS data, both rates appear to explain the rise in unemployment. This balanced contribution also characterizes the first 1999Q1-2001Q4 expansion featured by a decline in unemployment, whatever the dataset considered. The steady period until 1998 confirms this balanced impression. However, the job finding rate during the expansion 2006Q1-2007Q4 appears more active in the decrease in the unemployment rate in both Figures 3 and 4: more unemployment outflows result in a lower unemployment rate. The importance of the job finding rate seems even greater during the 2008Q1-2009Q4 recession: the surge in steady state unemployment is closely matched by a falling job finding rate. It must be noticed that this apparent change in the relative contribution of the job finding rate at the end of the 2000's was already present during the cyclical episode at the beginning of this decade (Figure 3).

Figure 3: Administrative data $(\mathrm{FH})$ : contribution of the separation (upper part, $d u_{t}^{S S}{ }^{E U}$ ) and finding (lower part, $d u_{t}^{S S}{ }^{U E}$ ) rates (in bold) to steady state unemployment $\left(d u_{t}^{S S}\right)$
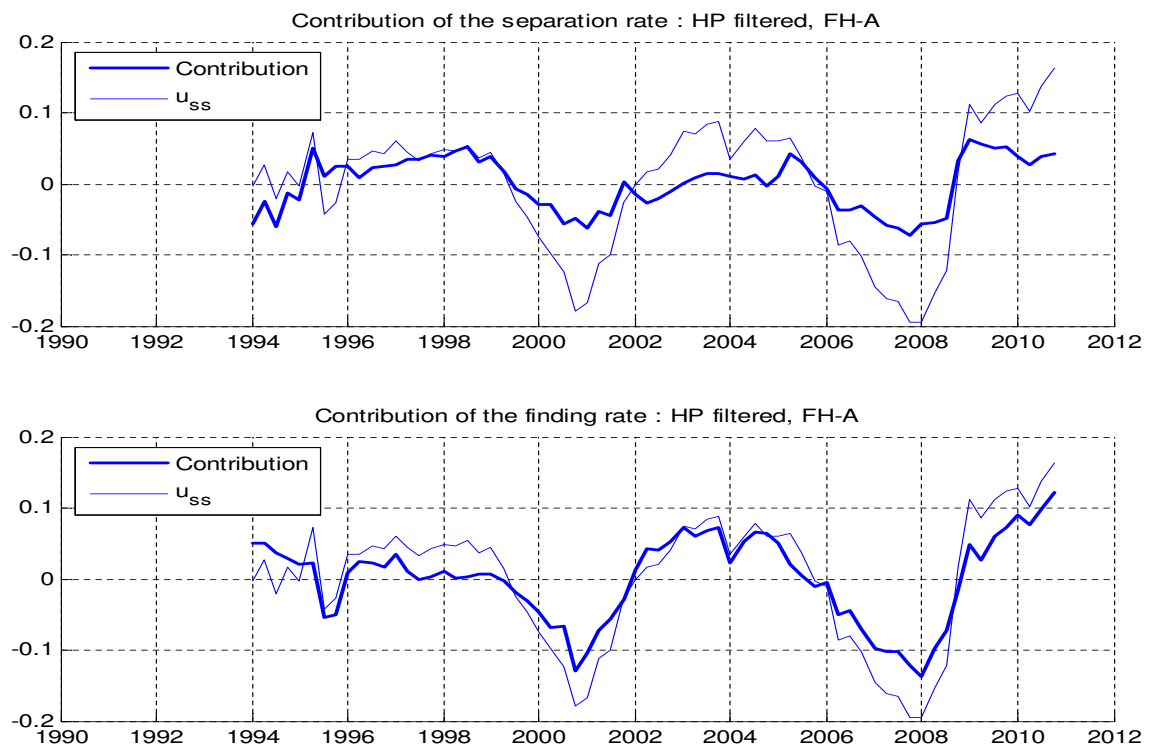
Figure 4: LFS: contribution of the separation (upper part, $d u_{t}^{S S \_}{ }^{E U}$ ) and finding (lower part, $\left.d u_{t}^{S S \_U E}\right)$ rates (in bold) to steady state unemployment $\left(d u_{t}^{S S}\right)$
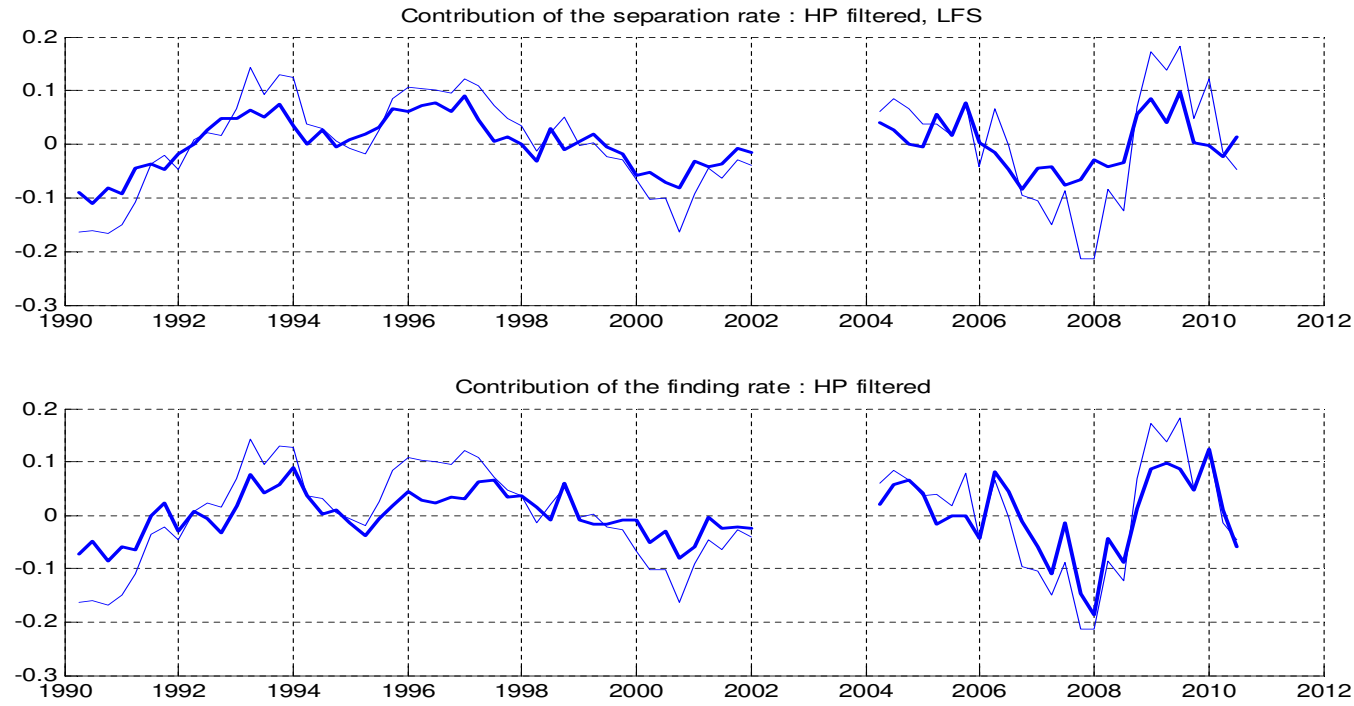

Table 3: Contribution of separation rates to fluctuations in steady state unemployment $\left(\beta^{E U}\right)$

\begin{tabular}{lcccc}
\hline \hline period & $1990-2002$ & $1994-2002$ & $2004-2010$ & $1994-2010$ \\
\hline FH (administrative data) & NA & 52 & 35 & 35.5 \\
LFS & 55.5 & 51.9 & 35.5 & NA \\
\hline \hline
\end{tabular}

Table 3 shows the quantitative contribution of the separation rate $\beta^{E U}$. The contribution of the job finding rate $\beta^{U E}$ is almost exactly the complement to 1 of $\beta^{E U}$, as we decompose changes in the steady state dynamics. Firstly, let us consider the results for the administrative data. Over all the period 1994-2010, the job finding rate explains two-thirds of the unemployment cyclical variations. This share is more balanced when considering the last years of the 1990 decade. These results are confirmed when considering LFS data. Consistently with the visual inspection of Figures 3 and 4 , the job finding rate becomes the dominant contributor to the unemployment dynamics in the 2000's, whereas both transition rates play an important role in the previous decade. Moreover, this increasing importance of the job finding rate during the last decade is true both in recession and in expansion, as can be seen in Table 4. 
Table 4: Contribution of separation rates to fluctuations in steady state unemployment $\left(\beta^{E U}\right)$

\begin{tabular}{lccccc}
\hline \hline & & Recessions & \multicolumn{2}{c}{ Expansions } \\
period & 1990Q4-1994Q2 & 2001Q4-2004Q1 & 2008Q1-2009Q4 & 1999Q1-2001Q4 & 2006Q1-2007Q4 \\
\hline FH (administrative data) & NA & 23.5 & 40.1 & 43.3 & 34.2 \\
LFS & 50.8 & NA & 39.6 & 58.8 & 5.9 \\
\hline \hline
\end{tabular}

\subsection{Analysis of actual unemployment}

Because of low inflow and outflow rates, actual unemployment may be not well proxied by its steady state value. Indeed, comparing the steady state and the actual unemployment rates in Figures 5 and 6 shows that the former lead the latter around the business cycle turnovers, when unemployment is changing fast.

Figure 5: Administrative date $(\mathrm{FH})$ : steady state unemployment ( $u^{S S}$ in bold) vs. actual unemployment $(u)$

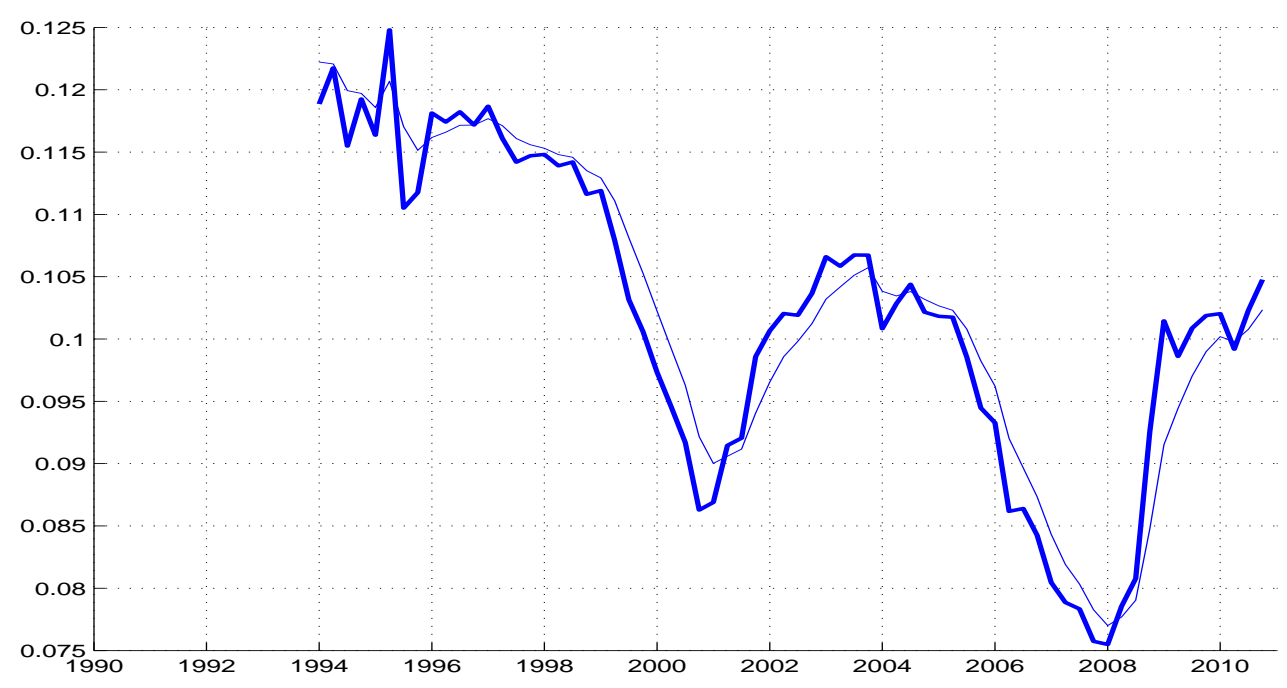

We then consider the unemployment dynamics implied by Equation (1), which takes into account the deviations from the unemployment steady state. Consistently to the method we used in the static analysis case, we consider the hypothetical unemployment dynamics using Equation (1) that hold the separation or the job finding rates constant at their historical averages. This approach allows us to focus on the HP component of unemployment instead on the first-differences.

More precisely we first integrate equation (1) over 3 months (instantaneous transition rates are averaged over one quarter). This yields the following law of motion of the quarterly 
Figure 6: LFS : steady state unemployment $\left(u^{S S}\right.$ in bold) vs. actual unemployment $(u)$

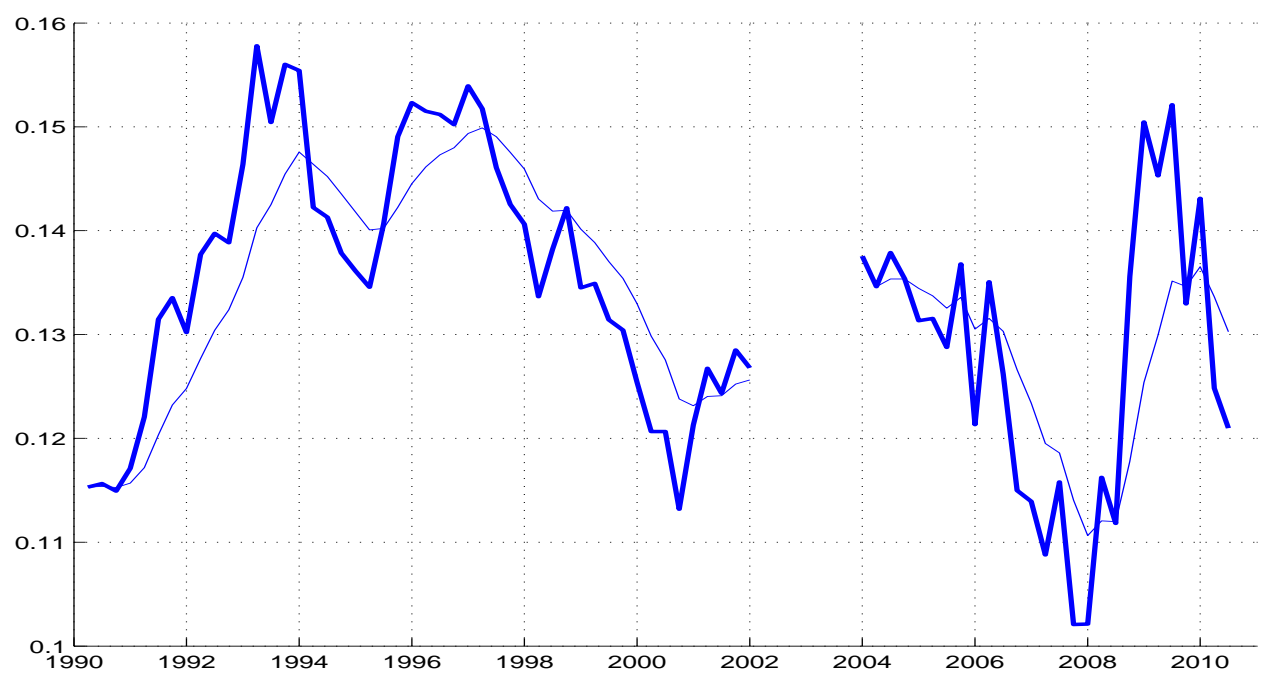

unemployment rate (in the following $t$ stands for quarter):

$$
u_{t+1}=\left(1-\exp \left(-3\left(\lambda_{t}^{E U}+\lambda_{t}^{U E}\right)\right)\right) \frac{\lambda_{t}^{E U}}{\lambda_{t}^{E U}+\lambda_{t}^{U E}}+\exp \left(-3\left(\lambda_{t}^{E U}+\lambda_{t}^{U E}\right) u_{t}\right.
$$

Note that high inflow and outflow rates imply that the unemployment rate is close to its steady state. Secondly the hypothetical unemployment rates that hold the separation or job finding rate constant $\left(\bar{\lambda}^{E U}\right.$ and $\left.\bar{\lambda}^{U E}\right)$ are computed recursively using :

$$
\begin{aligned}
& u_{t+1}^{E U}=\left(1-\exp \left(-3\left(\bar{\lambda}^{E U}+\lambda_{t}^{U E}\right)\right)\right) \frac{\bar{\lambda}^{E U}}{\bar{\lambda}^{E U}+\lambda_{t}^{U E}}+\exp \left(-3\left(\bar{\lambda}^{E U}+\lambda_{t}^{U E}\right) u_{t}^{E U}\right. \\
& u_{t+1}^{U E}=\left(1-\exp \left(-3\left(\lambda_{t}^{E U}+\bar{\lambda}^{U E}\right)\right)\right) \frac{\lambda_{t}^{E U}}{\lambda_{t}^{E U}+\bar{\lambda}^{U E}}+\exp \left(-3\left(\lambda_{t}^{E U}+\bar{\lambda}^{U E}\right) u_{t}^{E U}\right.
\end{aligned}
$$

with initial unemployment rates defined as below:

$$
\begin{aligned}
& u_{0}^{E U}=\frac{\bar{\lambda}^{E U}}{\bar{\lambda} E U+\lambda_{0}^{U E}} \\
& u_{0}^{U E}=\frac{\lambda_{0}^{E U}}{\lambda_{0}^{E U}+\bar{\lambda}^{U E}}
\end{aligned}
$$

As in Elsby et al. (2008), iterating on both equations (13 and (14) makes the actual unemployment rate dependent on current and past values of separation and finding rates. Figures 
7 and 8 are quite consistent with those relative to the steady state unemployment analysis. In the early part of the sample, cyclical unemployment is explained by the two hypothetical dynamics in a very similar way. The contribution of the job finding rate appears to rise at the end of the sample: job finding prospects seem to drive the 2006 expansion and the 2008 recession.

Figure 7: Administrative data (FH): contribution of the separation (upper part, $d u_{t}^{E U}$ ) and finding (lower part, $d u_{t}^{U E}$ ) rates (in bold) to actual unemployment $\left(d u_{t}\right)$
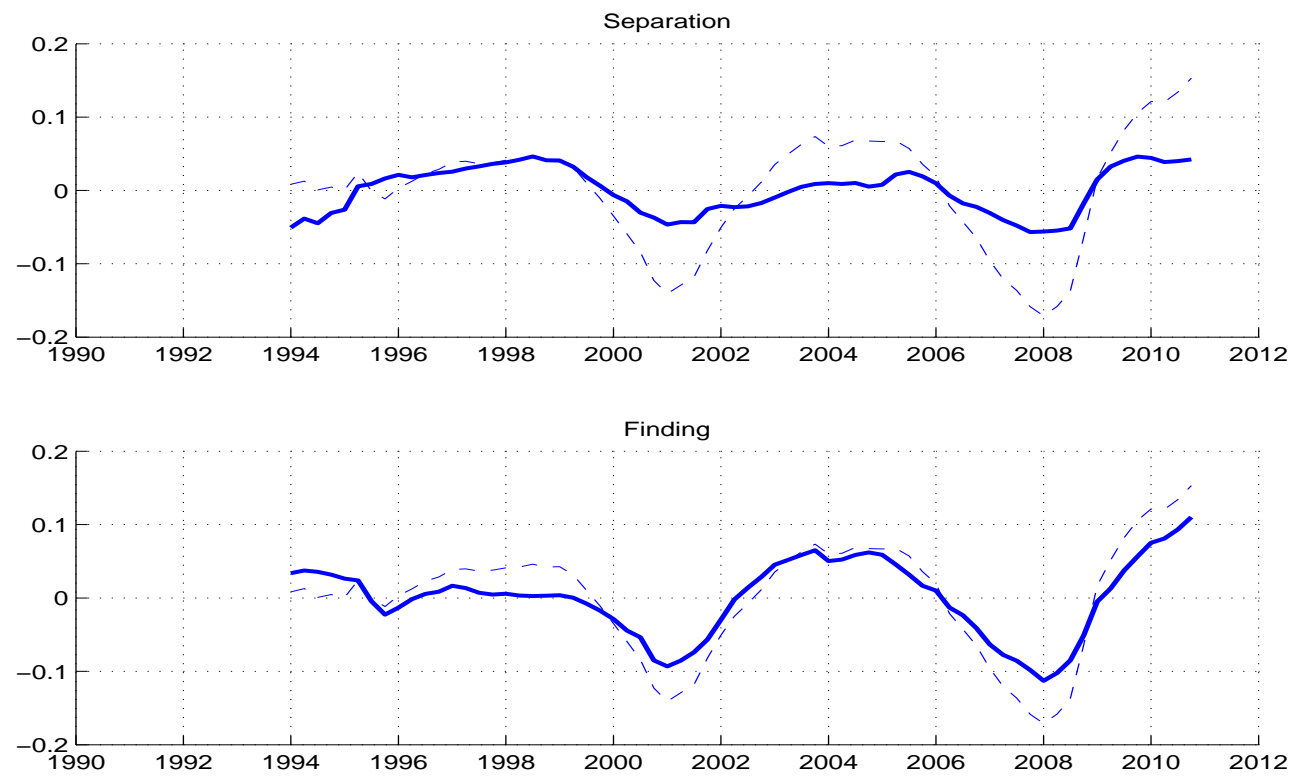

Table 5 shows the estimated contribution of separations after implementing the dynamic analysis. This method consists in regressing detrended counterfactual unemployment on detrended actual unemployment, using the Hodrick-Prescott filter for detrending with a smoothing parameter of $10^{5}$. Table 5 conveys the same picture of a balanced view on the relative contributions of the finding and separation rates in the 1990's, with a greater contribution of the job finding rate in recent years. However, taking into account the unemployment dynamics leads to a higher influence of the separation rate, which then appears slightly more important when considering higher business cycle frequencies, which echoes Elsby et al. (2008)'s results on French data.

Our stress on the greater role of the job finding in France is consistent with the recent changes in French labor market institutions (aimed at encouraging fixed-term contracts and temporary work), which may have reduced, at least partially, the gap from the US labor market. On the other hand, this evidence is rather against the received wisdom that the cyclical role of the job separation rate would be limited in countries with strict employment protection laws and low labor reallocations, typically during the 1990's in France: existing 
Figure 8: LFS : contribution of the separation (upper part, $d u_{t}^{E U}$ ) and finding (lower part, $\left.d u_{t}^{U E}\right)$ rates (in bold) to actual unemployment $\left(d u_{t}\right)$
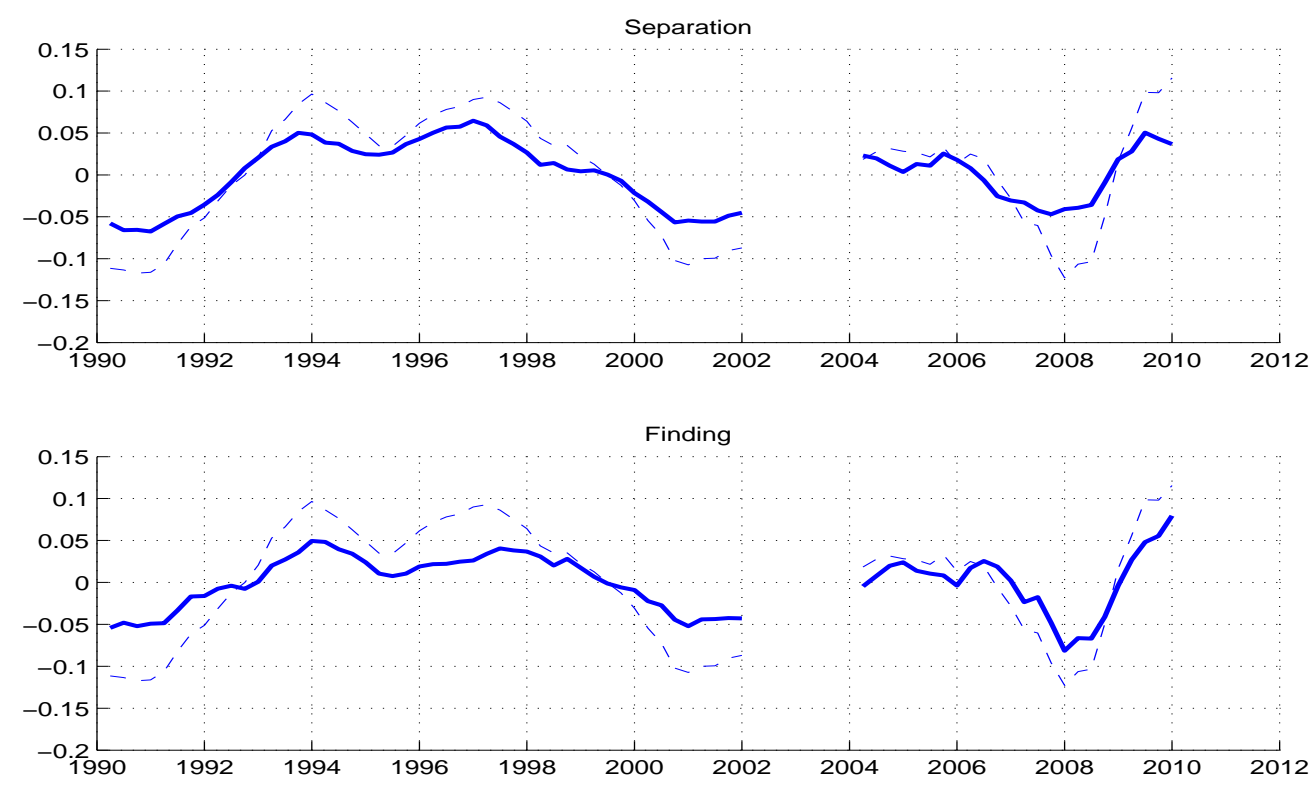

Table 5: Contribution of the separation rate (job finding rate) to fluctuations in actual unemployment

\begin{tabular}{lcccc}
\hline \hline period & $1990-2002$ & $1994-2002$ & $2004-2010$ & $1994-2010$ \\
\hline FH (administrative data) & NA & $64(39)$ & $35(62)$ & $34(64)$ \\
LFS & $57(43)$ & $55(44)$ & $42(57)$ & NA \\
\hline \hline
\end{tabular}

models of unemployment flows do not necessarily imply that firing costs limit the contribution of inflows to changes in unemployment. As pointed out by Elsby et al. (2008), the relative volatility of separation and finding rates depends on three elasticities : the elasticity of the inflow rate with respect to the reservation productivity, the elasticity of the value of a new hire with respect to aggregate productivity and the elasticity of the hiring cost with respect to the outflow rate. Further investigation of this important point on theoretical grounds is left for further research.

\section{Conclusion}

The contribution of the job finding rate amounts to about two-thirds of the unemployment dynamics. The French labor market is not so far from the US labor market as analyzed by Shimer (2012), as far the cyclicality of the job finding and separation rates is concerned. 
This is quite surprising, as the French labor market has much lower turnovers on average than the US, and institutions such as unemployment insurance and employment protection are far more prevalent in France than in the US. Does it mean that labor market institutions matter less for cyclical adjustments than for equilibrium unemployment? Instead of giving a highly hypothetical answer at this stage, we favor the idea that more theoretical work must be done in the future on this issue.

On the empirical side, we show that the cyclical contribution of the transition rates to the unemployment dynamics is sensitive to the filter used. This point is quite trivial in applied macroeconomics. But it questions some previous studies which extensively rely on first-differentiation. We subscribe to Shimer (2012)'s view that the unemployment cycle is long-lasting and HP filtering with a high smoothing parameter is more appropriate. We acknowledge that it still remains a controversial empirical issue.

Our analysis ignores transitions to and from inactivity. As shown in Smith (2011) on UK workers' flows, this assumption is not innocuous. Indeed, transitions of young and old workers are likely to be sensitive to labor market conditions, but they are disregarded in a two state analysis as young workers classify themselves as students and old workers as retirees (even when they are looking for a job). Incorporating more precisely young workers' transitions is especially important when analyzing the recent crisis: this age group has been hit hard. It is also important to incorporate them in our analysis as they are particularly affected by some labor market institutions. As Blanchard \& Landier (2002) point out, temporary contracts particularly affect young workers in France. Analyzing the interaction between institutions and labor market dynamics calls for considering such particular groups.

As a consequence, in a future study, we want to extend the three-state approach developed by Smith (2011) to French data. We will do so with LFS which is the only dataset that provides accurate information on non-participation. This is why it was particularly important to gauge the quality of LFS data in this paper by comparing it with administrative data. 


\section{APPENDIX}

\section{A Correcting for recall errors}

One important drawback of survey data is measurement error. In particular in the case of labor market surveys, individuals may find it difficult to recognize themselves in one labor market status rather than another one (typically between unemployment and out of the labor force) and/or to recall past status. The first difficulty leads to classification error and the second one to recall error. Empirically, the extent of classification and recall errors in labor market transition data can be documented by comparing survey responses with external sources such as administrative data, or comparing responses on the labor status prevailing at one particular date but declared in different interviews. In the case of the US, Horvath (1982) compares monthly responses to CPS interviews with retrospective information derived from its March supplement and shows that recall errors bias downwards aggregate unemployment. Akerlof \& Yellen (1985) and Levine (1993) use the same data and show that unemployment is more understated among individuals with weak attachment to the labor market, when unemployment is less salient or when unemployment spells are shorter. Using reinterviews in CPS data, Poterba \& Summers (1986) document classification error. Systematic conflicting information depending on the interview date is also found in the European Household Panel Survey (Kyyrä \& Wilke (2011)), in the German Socio Economic Panel (Jürges (2007)), in the British Household Panel Survey (Paull (2002)) or in the 19901993 French Labor Survey (Magnac \& Visser (1999)). While recall errors affect estimates of aggregate unemployment, they may also bias transition estimates. For example, Magnac and Visser find that employment durations corrected for recall errors are lower.

Except for Akerlof \& Yellen (1985), who suggest that the recall bias is less important when unemployment is increasing, there is little evidence that measurement errors are cyclically sensitive. Smith (2011) and Fujita \& Ramey (2009) even conclude that classification errors in transition rates do not induce a cyclical bias that could affect their analysis of unemployment volatility. Fujita and Ramey apply Poterba and Summers' correction while Smith applies Paull's correction. In the French LFS, classification error is not such an issue : during the first part of the interview, the current situation is extensively discussed ,so that individuals should be aware of labor market classification concepts when the retrospective calendar is asked for at the end of the interview. Like Magnac and Visser, we are concerned by recall errors in the retrospective calendar. Unfortunately, Magnac and Visser's method to correct for recall errors cannot be applied in our context. First, they assume that transition rates are constant over at least two years while we analyze higher frequency movements. Secondly, in the new LFS (since 2003), one individual situation is not observed both contemporaneously and with a one year-lag. This precludes the possibility of building Magnac and Visser's individual recall error matrix. However, in the new LFS (since 2003), different cohorts are interviewed in every month of the year. This higher frequency enables us to compare aggregate status and transition rates at one point in time for different recall durations (for different interview 
Table 6: Interview plans of the new LFS (since 2003)

\begin{tabular}{|c|c|c|c|c|c|c|c|c|c|c|c|c|c|c|}
\hline date $\backslash$ cohort & $\begin{array}{l}\text { Lి } \\
\text { هิ } \\
\text { ष্ } \\
\end{array}$ & 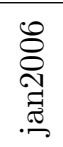 & 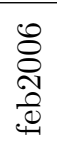 & 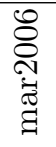 & 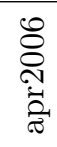 & 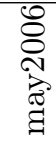 & $\begin{array}{l}\mathscr{E} \\
\text { ज. } \\
\stackrel{\Xi}{\text { I }}\end{array}$ & $\begin{array}{l}\stackrel{8}{8} \\
\text { N } \\
. \Xi\end{array}$ & 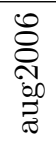 & 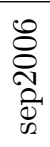 & 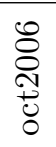 & 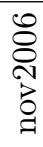 & 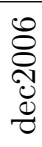 & 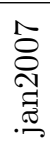 \\
\hline dec2005 & $\mathrm{X}$ & $\mathrm{X}$ & $\mathrm{X}$ & $\mathrm{X}$ & $\mathrm{X}$ & $\mathrm{X}$ & $\mathrm{X}$ & $\mathrm{X}$ & $\mathrm{X}$ & $\mathrm{X}$ & $\mathrm{X}$ & $\mathrm{X}$ & & \\
\hline jan2006 & & $\mathrm{X}$ & $\mathrm{X}$ & $\mathrm{X}$ & $\mathrm{X}$ & $\mathrm{X}$ & $\mathrm{X}$ & $\mathrm{X}$ & $\mathrm{X}$ & $\mathrm{X}$ & $\mathrm{X}$ & $\mathrm{X}$ & $\mathrm{X}$ & \\
\hline feb2006 & & & $\mathrm{X}$ & $\mathrm{X}$ & $\mathrm{X}$ & $\mathrm{X}$ & $\mathrm{X}$ & $\mathrm{X}$ & $\mathrm{X}$ & $\mathrm{X}$ & $\mathrm{X}$ & $\mathrm{X}$ & $\mathrm{X}$ & $\mathrm{X}$ \\
\hline mar2006 & & & & $\mathrm{X}$ & $\mathrm{X}$ & $\mathrm{X}$ & $\mathrm{X}$ & $\mathrm{X}$ & $\mathrm{X}$ & $\mathrm{X}$ & $\mathrm{X}$ & $\mathrm{X}$ & $\mathrm{X}$ & $\mathrm{X}$ \\
\hline apr2006 & & & & & $\mathrm{X}$ & $\mathrm{X}$ & $\mathrm{X}$ & $\mathrm{X}$ & $\mathrm{X}$ & $\mathrm{X}$ & $\mathrm{X}$ & $\mathrm{X}$ & $\mathrm{X}$ & $\mathrm{X}$ \\
\hline may2006 & & & & & & $\mathrm{X}$ & $\mathrm{X}$ & $\mathrm{X}$ & $\mathrm{X}$ & $\mathrm{X}$ & $\mathrm{X}$ & $\mathrm{X}$ & $\mathrm{X}$ & $\mathrm{X}$ \\
\hline jun2006 & & & & & & & $\mathrm{X}$ & $\mathrm{X}$ & $\mathrm{X}$ & $\mathrm{X}$ & $\mathrm{X}$ & $\mathrm{X}$ & $\mathrm{X}$ & $\mathrm{X}$ \\
\hline jul2006 & & & & & & & & $\mathrm{X}$ & $\mathrm{X}$ & $\mathrm{X}$ & $\mathrm{X}$ & $\mathrm{X}$ & $\mathrm{X}$ & $\mathrm{X}$ \\
\hline aug2006 & & & & & & & & & $\mathrm{X}$ & $\mathrm{X}$ & $\mathrm{X}$ & $\mathrm{X}$ & $\mathrm{X}$ & $\mathrm{X}$ \\
\hline sep2006 & & & & & & & & & & $\mathrm{X}$ & $\mathrm{X}$ & $\mathrm{X}$ & $\mathrm{X}$ & $\mathrm{X}$ \\
\hline oct2006 & & & & & & & & & & & $\mathrm{X}$ & $\mathrm{X}$ & $\mathrm{X}$ & $\mathrm{X}$ \\
\hline nov2006 & & & & & & & & & & & & $\mathrm{X}$ & $\mathrm{X}$ & $\mathrm{X}$ \\
\hline dec2006 & & & & & & & & & & & & & $\mathrm{X}$ & $\mathrm{X}$ \\
\hline jan2007 & & & & & & & & & & & & & & $\mathrm{X}$ \\
\hline
\end{tabular}

Reading: $\mathrm{X}$ indicates that the cohort (in columns) is interviewed about its labor market status (in rows).

dates) and thus estimate the extent of aggregate recall bias. Based on those estimates, we then correct previous waves of the annual LFS (before 2002). In a nutshell, our method assumes that transition rates between the month just before the interview and the interview month are free of measurement error. It also assumes that recall errors are not cyclical.

To better understand our method for computing aggregate recall bias, consider Table 6 which describes the LFS interview plan after the 2003 redesign. Each month, one individual is interviewed (in columns in the table) about her labor market status over the preceding year (dates are in rows). For example, the cohort interviewed in December 2006 (last but one column) declares her situation from January 2006 to December 2006. The interview plan means that, for one calendar month (or date), 12 cohorts declare their labor market status. For example, cohorts interviewed from January 2006 to December 2006 declare their labor market status prevailing in January 2006 (second row). Out of those 12 cohorts, situations declared by the Jan2006 cohort are the least biased and can be considered as the truth. Labor market outcomes of January 2006 are reported by individuals surveyed in jan2006 (without recall error) and in Feb2006 (with one month recall error). The differences observed between the two reports are, in our view, due only to the one lag recall error. We repeat the procedure for 2-month, 3-month, ... recall error for January 2006 and consider February 2006, etc ... We thereby obtain a time-series for one-month, two-month, three-month, etc., recall errors and estimate the average recall error for each lag using OLS.

In Figure 9, we illustrate the extent of the recall bias for the unemployment rate, the 
Table 7: Difference between outcomes recalled with lags and contemporaneous outcomes

\begin{tabular}{lccc}
\hline \hline Recall lags (in months) & unemployment rate & separation & finding \\
\hline 1 & -0.000962 & -0.001305 & 0.001281 \\
& $(0.585748)$ & $(0.014647)$ & $(0.716783)$ \\
2 & -0.00251 & -0.001351 & -0.000915 \\
& $(0.193071)$ & $(0.003103)$ & $(0.748400)$ \\
3 & -0.004282 & -0.001929 & -0.005047 \\
& $(0.021851)$ & $(0.000011)$ & $(0.103947)$ \\
4 & -0.005494 & -0.002483 & -0.006914 \\
& $(0.003092)$ & $(0.000000)$ & $(0.036158)$ \\
5 & -0.005877 & -0.002924 & -0.002402 \\
& $(0.000881)$ & $(0.000000)$ & $(0.458616)$ \\
6 & -0.007136 & -0.002281 & -0.008755 \\
& $(0.000031)$ & $(0.000001)$ & $(0.003390)$ \\
7 & -0.007829 & -0.002843 & -0.005556 \\
& $(0.000071)$ & $(0.000000)$ & $(0.127832)$ \\
8 & -0.008554 & -0.003553 & -0.010268 \\
& $(0.000012)$ & $(0.000000)$ & $(0.004590)$ \\
9 & -0.008555 & -0.004115 & -0.009996 \\
& $(0.000003)$ & $(0.000000)$ & $(0.001798)$ \\
10 & -0.008252 & -0.004654 & -0.010731 \\
& $(0.000058)$ & $(0.000000)$ & $(0.000463)$ \\
\hline \hline
\end{tabular}

Source: LFS. Note: average computed for cohorts from January 2006 to December 2009.

separation rate and the finding rate. The first point gives the average for all cohorts of the contemporaneous declaration. If we denote the unemployment rate declared by the $c$ cohort about month $t U_{t}^{c}$, the first point in the graph is $\sum_{m} U_{t=m}^{c=m}$. We consider this estimate as the truth. Thus the unemployment rate is $11 \%$ on average from January 2004 to December 2009. The second point is the unemployment rate recalled with a one-month lag $\left(\sum_{m} U_{t=m}^{c=m+1}\right)$. As can be seen in Figure 9, it is lower than the contemporaneous $U$ rate. However the difference is quantitatively small and not statistically significant. The one lag recall error estimate is shown in the first row and first column of Table 7 with its standard error. Figure 9 shows that the recalled unemployment, separation and finding rates are generally decreasing with the recall lag. Table 7 shows that unemployment, separation and finding recall errors are all statistically significant from the six-month lag onwards, which means that individuals actually tend to forget episodes of separations and findings.

We use the post-2004 recall error estimates to correct the LFS before 2002. For the LFS before 2002, there is only one cohort interviewed each year, namely in March, so that contemporaneous rates are available only once a year. To recover unbiased estimates, recalled 
outcomes are corrected with the post-2004 estimates. To assess the extent of our correction, we plot in Figure 10 steady state unemployment rates before and after recall error correction. The correction of transition rates implies, as expected, a higher unemployment rate. 
Figure 9: Outcomes by recall lags
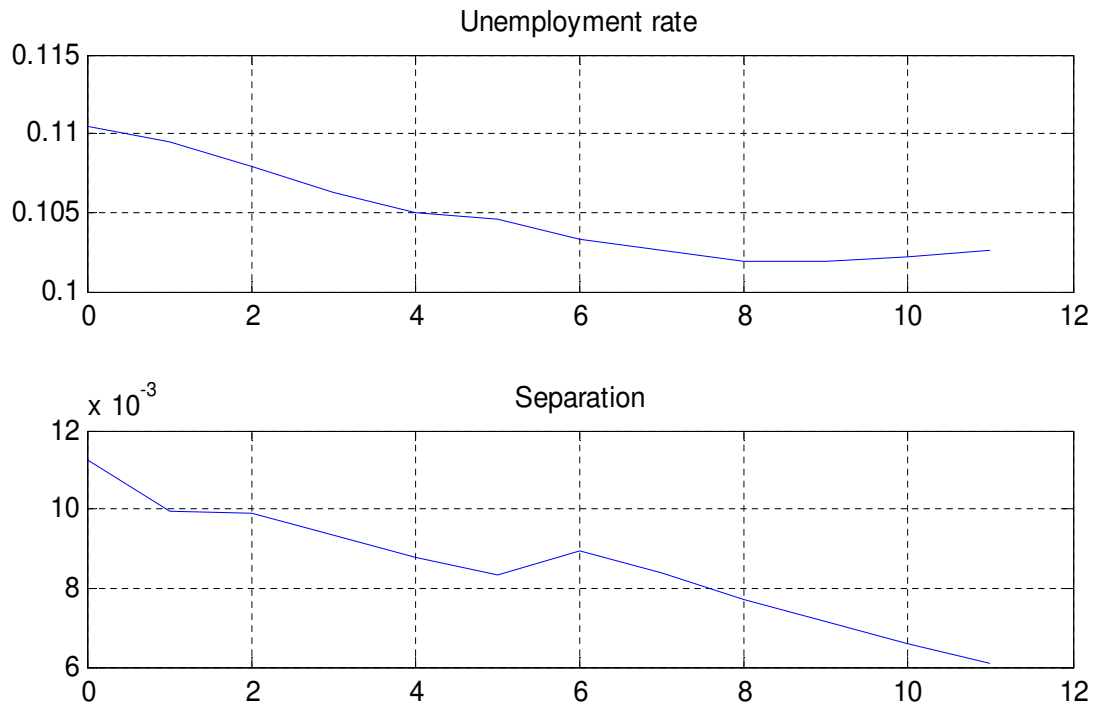

Finding

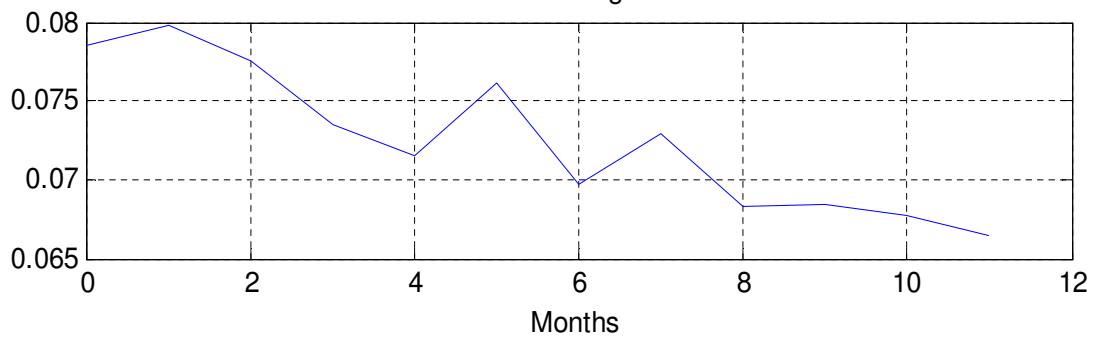

Source: LFS. Note: average computed for cohorts from January 2006 to December 2009. 11th lag outcomes are extrapolation from lower lag outcomes. 
Figure 10: Steady state unemployment

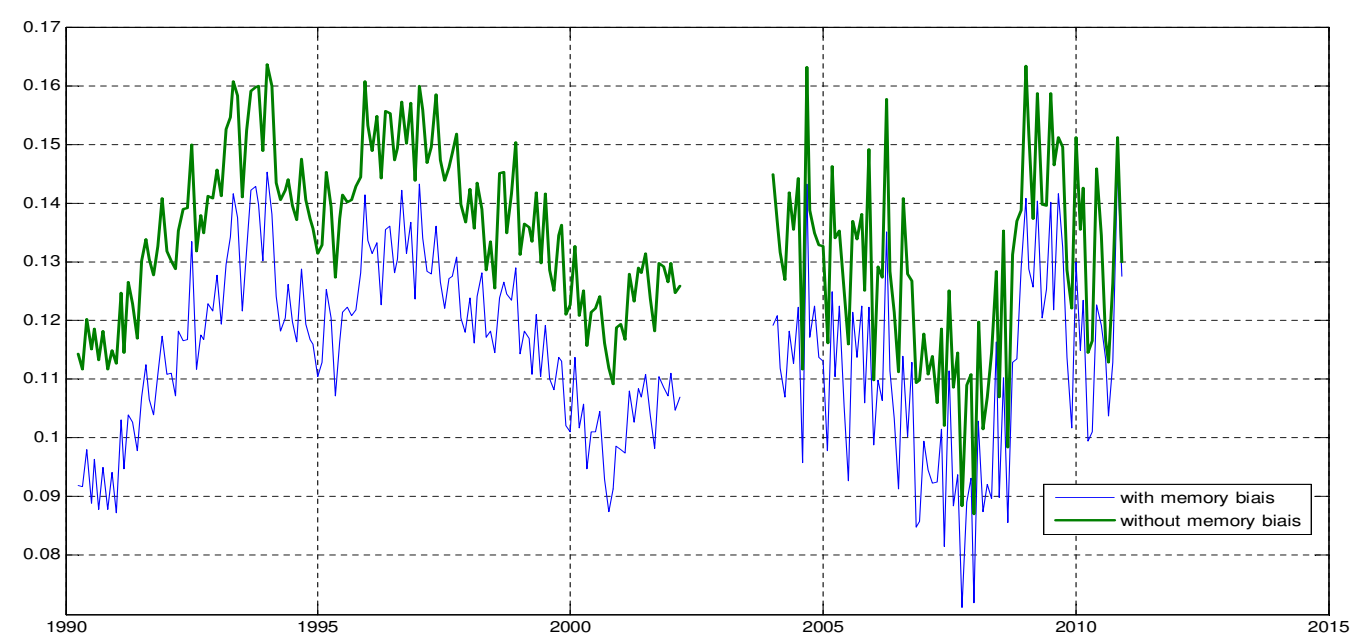


Table 8: Impact of filtering method on $\beta$, CPS data, 1967Q2-2010Q4

\begin{tabular}{|l|cc|cc|}
\hline & \multicolumn{2}{|c|}{ Separation } & \multicolumn{2}{c|}{ Finding } \\
& Shimer counterfactual & Fujita Ramey & Shimer counterfactual & Fujita Ramey \\
\hline HP filter $\lambda=10^{5}$ & 0.35017 & 0.34962 & 0.65192 & 0.65342 \\
HP filter $\lambda=1600$ & 0.38923 & 0.3888 & 0.61316 & 0.61341 \\
First Difference & 0.49588 & 0.49555 & 0.50666 & 0.5066 \\
\hline
\end{tabular}

\section{B The role of detrending method on US data}

Using US CPS data between 1967Q2 and 2010Q4, we compute the separation and job finding rates as in Fujita \& Ramey (2009) (hybrid two-state). Table 8 shows the $\beta$ analyis of steady state unemployment on Shimer (2012)'s counterfactual unemployment and Fujita \& Ramey (2009)'s exact analysis (in columns) using different filtering methods to identify the business cycle component (HP filter $\lambda=10^{5}$, HP filter $\lambda=1600$, First Difference). 


\section{Actual and ILO unemployment rates}

Actual and ILO unemployment rates are shown in Figure 11.

Figure 11: Actual and ILO unemployment rates

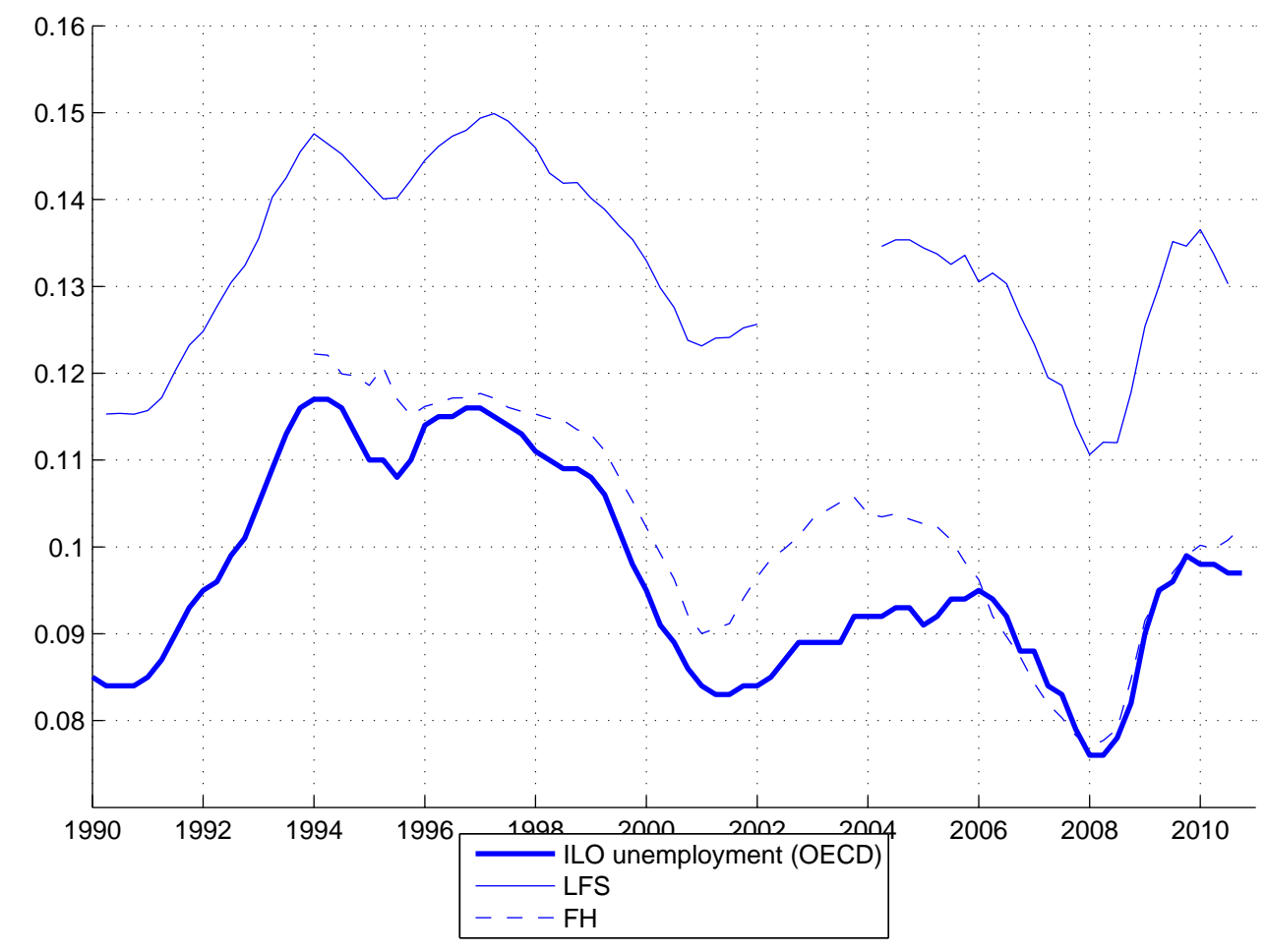




\section{References}

Abdouni, S., Defresne, M., Deroyon, T., Dubois, Y. \& Barbanchon, T. L. (2011), Les inscriptions a pole emploi : une analyse retrospective des evolutions en 2009, Dares analyses 2011-008, French Ministry of Labor.

Akerlof, G. A. \& Yellen, J. L. (1985), 'Unemployment through the filter of memory', The Quarterly Journal of Economics 100(3), 747-73.

Allard, G. (2005), Measuring job security over time: In search of a historical indicator, Instituto de Empressa Working Paper WP-05, Instituto de Empressa.

Blanchard, O. \& Landier, A. (2002), 'The perverse effects of partial labor market reform: Fixed duration contracts in france', Economic Journal 112, 214-244.

Blanchard, O. \& Portugal, P. (2001), 'What hides behind an unemployment rate: Comparing portuguese and u.s. labor markets', American Economic Review 91(1), 187-207.

Elsby, M., Hobijn, B. \& Sahin, A. (2008), Unemployment dynamics in the OECD, NBER Working Paper 14617, NBER.

Elsby, M. W. L., Michaels, R. \& Solon, G. (2009), 'The ins and outs of cyclical unemployment', American Economic Journal: Macroeconomics 1(1), 84-110.

Fujita, S. \& Ramey, G. (2009), 'The cyclicality of separation and job finding rates', International Economic Review 50(2), 415-430.

Horvath, F. W. (1982), 'Forgotten unemployment: Recall bias in retrospective data', Monthly Labor Review pp. 40-43.

Jürges, H. (2007), 'Unemployment, life satisfaction and retrospective error', Journal of the Royal Statistical Society Series A 170(1), 43-61.

Kyyrä, T. \& Wilke, R. A. (2011), On the reliability of retrospective unemployment information in european household panel data, Working Papers 21, Government Institute for Economic Research Finland (VATT).

Levine, P. B. (1993), 'Cps contemporaneous and retrospective unemployment compared', Monthly Labor Review pp. 33-39.

Magnac, T. \& Visser, M. (1999), 'Transition models with measurement errors', The Review of Economics and Statistics 81(3), 466-474.

Paull, G. (2002), Biases in the reporting of labour market dynamics, Working Papers 02/10, Institute for Fiscal Studies. 
Petrongolo, B. \& Pissarides, C. (2008), 'The ins and outs of european unemployment', American economic review 98(2), 256-262.

Poterba, J. M. \& Summers, L. H. (1986), 'Reporting errors and labor market dynamics', Econometrica 54(6), 1319-38.

Shimer, R. (2012), 'Reassessing the ins and outs of unemployment', Review of Economic Dynamics 15, 127-148.

Smith, J. (2011), 'The ins and outs of UK unemployment', Economic Journal 121, 402-444. 